\begin{tabular}{c} 
International Journal of Engineering \& Technology, $7(4.38)(2018)$ 1055-1061 \\
International Journal of Engineering \& Technology \\
Website: $w$ ww.sciencepubco.com/index.php/IJET \\
Research paper \\
\hline
\end{tabular}

\title{
Social Process and Cohabitation: A Trend of the New Generations
}

\author{
Wilailak Ounjit (Laila) \\ Faculty of Humanities and Social Sciences, \\ Mahasarakham University, Kantarawichai District, Maha Sarakham 44150, Thailand
}

\begin{abstract}
Cohabitation is a phenomenon which has taken place relatively recently in Thailand and is likely to spread and increase gradually in the future. Currently there are very few systematic studies on cohabitation among adolescents in Thailand and information has been obtained mostly from public media such as; newspapers, television programs and the internet. This qualitative and quantitative research aims to study the social process and cohabitating among Thai Adolescents. One thousand three hundred and twenty-eight respondents, who were in years one to four of their studies, were selected to participate, using a stratified random sampling technique. The survey was designed to use questionnaires to gather information from the respondents. In addition, semi-structured interviews were carried out with students, to provide a more in-depth understanding of the issues under study. The conceptual framework for this study was derived from empirical observation and intuition; imitation, social contact and social control. The results of the study revealed that there is a prevalence of cohabitation among Thai Adolescents. The significant factors that influenced the students' cohabitation are foreign cultures, including American, Japanese and Korean culture (45.12\%). Their peers' cohabitation did not play a key role in the respondents wanting to experience cohabitation. The belief that traditional Thai women should reserve themselves for marriage was accepted among respondents $(44.75 \%)$. Many of the respondents indicated that their families opposed cohabitation. Additionally, sexual behavior of Thai women is limited in the traditional norm. Cohabitation is considered as untraditional and teenagers are dating each other secretly (42.13\%). The information available and institutional education on the prevention of Sexually Transmitted Infections and Unwanted Pregnancies, allow adolescents to better understand the consequences of pre-marital sexual relationships (45.92\%).
\end{abstract}

Keywords: Social Process, Cohabitation, Imitation, Social Contact, Social Control

\section{Introduction}

Thai society and culture have undergone dramatic changes in terms of economy, society, value, culture and tradition as well as premarital cohabitation among adolescents, in recent years, when compared to the past. Premarital cohabitation is defined as; a living arrangement where a man and a woman who love or have affection for each other, live together in the same accommodation, have a sexual relationship and generally cohabit as a married couple, without undergoing formal marriage registration. Premarital cohabitation exists in various spheres of society from the very poor to the very rich. The trend of broad acceptance of premarital cohabitation has resulted in declining marriage rates and is considered to be a global phenomenon. 1

Regarding social processes and premarital cohabitation among Thai adolescents, those who cohabit nowadays may will continue to cause social issues. Social processes also play a significant part and are particularly relevant to premarital cohabitation among Thai adolescents because they influence people in their social activities and affect the relationships and lifestyle of people in their society. They can also introduce both positive and negative changes. The adoption of foreign culture brings impact towards imitational behavior in teenagers, for example, teenagers become less reserved, greet each other by hugging, kissing, showing affection in public and living together before marriage. This is evident in the change of value and customs seen among female teenagers in terms of being less reserved than in the past. The family is also a central institution in the formation of sexual attitudes and behavior because it provides role models, social and economic environments and standards of sexual conduct.2-4

\section{Objectives}

The purpose of this paper is to examine the Social Processes that influence premarital cohabitations among Thai adolescents.

\section{Methodology}

The present research is an exploratory research. Quantitative and qualitative data was collected using questionnaires and personal interviews. The population consisted of 3,423 undergraduate students in their first to fourth years in the Faculty of Humanities and Social Sciences of the university in Thailand. The sample group comprised 1,328 students. The researcher collected data by handing out closed questionnaires with rating scales, which allowed students to answer questions to obtain the facts. For the qualitative data collection, a semi-structured interview method was employed.

\section{Assessment of Research Tools}

The content validity of the questionnaire and interviews were assessed by three experts. The Content Validity Index (CVI) obtained was 0.86 . The research tools were tried out with 60 under- 
graduate students, 15 students from each year. The validity of the tools was then assessed.

\section{Collection of Data}

The data was collected from 1,328 first to fourth year students of the Faculty of Humanities and Social Sciences who enrolled in the academic year 2016. The researcher made appointments with the students on their availability and willingness to participate in the survey. After the students finished their classes, they completed the questionnaires which took 10-15 minutes. There were also 28 more students who volunteered for the interview. Each interview lasted between 30 to 40 minutes. After the data was collected, the research assistant checked each questionnaire and found there were 1,328 perfect for the analysis.

\section{Analysis of Data}

1. The frequency and percentage were employed for the analysis of the respondent's general information i.e. sex, age and education level.

2. The frequency, percentage, mean and standard deviation were used for the analysis of the social processes that influence the Thai adolescents' cohabitation.

\section{Analysis of Results}

This article analyzed the social processes and cohabitation arrangements among university students. It was found that the students in the sample group were female $(76.51 \%)$, aged 19 years $(27.33 \%)$, studying in year one $(40.89 \%)$, majoring in Thai language $(22.36 \%)$, having parents living together (76.66\%), being brought up in strict and observant households, in terms of sexual relationships $(37.35 \%)$, living in dormitories located outside the campus $(63.10 \%)$, receiving 4,001-5,000 Baht for their monthly allowances from parents $(40.14 \%)$, currently having no boyfriend/girlfriend (61.75\%), having no sexual experience (65.74\%), disagreeing with the concept of premarital cohabitation as seen as unnecessary $(42.55 \%)$.

Table 1: Social Processes and Cohabitation among University Students

\begin{tabular}{|c|c|c|c|c|}
\hline & $\begin{array}{l}\text { Social Processes influencing Co- } \\
\text { habitations among Thai Adoles- } \\
\text { cents }\end{array}$ & $\overline{\mathrm{x}}$ & S.D & Level \\
\hline 1. & $\begin{array}{l}\text { Actors and singers are the key role } \\
\text { models for imitation behaviors in } \\
\text { Thai teenagers such as cohabitation }\end{array}$ & 3.34 & 0.99 & $\begin{array}{c}\text { moderate } \\
\text { level }\end{array}$ \\
\hline 2. & $\begin{array}{l}\text { Foreign cultures including American, } \\
\text { Japanese and Korean cultures have } \\
\text { influences on premarital cohabita- } \\
\text { tions. }\end{array}$ & 3.55 & 0.94 & $\begin{array}{l}\text { High } \\
\text { level }\end{array}$ \\
\hline 3. & $\begin{array}{l}\text { Family members including relatives } \\
\text { and siblings have influences on pre- } \\
\text { marital cohabitations, for example, } \\
\text { relatives or siblings cohabit with their } \\
\text { boyfriends/girlfriends. }\end{array}$ & 3.16 & 1.02 & $\begin{array}{c}\text { moderate } \\
\text { level }\end{array}$ \\
\hline 4. & $\begin{array}{l}\text { Seeing friends cohabiting with their } \\
\text { boyfriends/girlfriends may influence } \\
\text { my decision to cohabit with my boy- } \\
\text { friend/girlfriend (supposing you are } \\
\text { not having a boyfriend/girlfriend) }\end{array}$ & 2.92 & 1.08 & $\begin{array}{c}\text { moderate } \\
\text { level }\end{array}$ \\
\hline 5. & $\begin{array}{l}\text { Most teenagers cohabit because of } \\
\text { social trends according to the saying } \\
\text { "everybody does it". }\end{array}$ & 3.42 & 1.15 & $\begin{array}{c}\text { moderate } \\
\text { level }\end{array}$ \\
\hline 6. & $\begin{array}{l}\text { Accessing the nightlife can lead to } \\
\text { have sexual relationship and cohabi- } \\
\text { tation eventually. }\end{array}$ & 4.06 & 0.95 & $\begin{array}{l}\text { High } \\
\text { level }\end{array}$ \\
\hline 7. & $\begin{array}{l}\text { Being with a person of the opposite } \\
\text { sex in a place out of sight of other } \\
\text { people may lead to sexual relation- } \\
\text { ship. }\end{array}$ & 3.94 & 0.97 & $\begin{array}{l}\text { High } \\
\text { level }\end{array}$ \\
\hline
\end{tabular}

\begin{tabular}{|c|l|c|c|c|}
\hline & $\begin{array}{l}\text { Social Processes influencing Co- } \\
\text { habitations among Thai Adoles- } \\
\text { cents }\end{array}$ & $\overline{\mathrm{x}}$ & S.D & Level \\
\hline 8. & $\begin{array}{l}\text { Residence is a risk factor for cohabi- } \\
\text { tation. }\end{array}$ & 3.68 & 0.98 & $\begin{array}{l}\text { High } \\
\text { level }\end{array}$ \\
\hline 9. & $\begin{array}{l}\text { Partying gives opportunity for male } \\
\text { and female teenagers to have physical } \\
\text { contact with each other. }\end{array}$ & 4.00 & 0.82 & $\begin{array}{l}\text { High } \\
\text { level }\end{array}$ \\
\hline 10. & $\begin{array}{l}\text { Going to other province with } \\
\text { friends of the opposite sex is consid- } \\
\text { ered as a social risk factor for sexual } \\
\text { relationship. }\end{array}$ & 3.53 & 1.01 & $\begin{array}{l}\text { High } \\
\text { level }\end{array}$ \\
\hline 11. & $\begin{array}{l}\text { Your family can accept the fact that } \\
\text { you live together with your partner } \\
\text { during your university life. }\end{array}$ & 2.39 & 1.17 & Low level \\
\hline 12. & $\begin{array}{l}\text { Sexual behavior of Thai women is } \\
\text { limited in traditional norm. Cohabita- } \\
\text { tion is considered as untraditional, } \\
\text { and teenagers are therefore dating } \\
\text { each other secretly. }\end{array}$ & 3.73 & 0.98 & $\begin{array}{l}\text { High } \\
\text { level }\end{array}$ \\
\hline 13. & $\begin{array}{l}\text { Arrangement of activity for preven- } \\
\text { tion of sexual risk behavior in educa- } \\
\text { tional institution allows adolescents } \\
\text { to gain good understanding on sexual } \\
\text { relationship. }\end{array}$ & 4.06 & 0.82 & $\begin{array}{l}\text { High } \\
\text { level }\end{array}$ \\
\hline 14. & $\begin{array}{l}\text { Living in a dormitory or away from } \\
\text { parents could expose students to high } \\
\text { risk of sexual behaviors. }\end{array}$ & 3.82 & 1.01 & $\begin{array}{l}\text { High } \\
\text { level }\end{array}$ \\
\hline 15. & $\begin{array}{l}\text { The value of "being reserved" should } \\
\text { be upheld. }\end{array}$ & 4.19 & 0.91 & $\begin{array}{l}\text { High } \\
\text { level }\end{array}$ \\
\hline & $\begin{array}{l}\text { High } \\
\text { level }\end{array}$ \\
\hline
\end{tabular}

From the above table, it was found that the university students had overall opinion rating towards social processes and premarital cohabitation among Thai adolescents particularly regarding social processes influencing premarital cohabitation being at a high level $(\bar{x}=3.59)$. When considering each individual item, the top three items were: the value of "being reserved" should be upheld $(\overline{\mathrm{x}}=$ 4.19), the information available and institutional education on the prevention of Sexually Transmitted Infections and Unwanted Pregnancies, allow adolescents to better understand the consequences of pre-marital sexual relationships, however, going to bars, restaurants, nightclubs, pubs or karaoke places, opens opportunities for sexual risk behavior, which had the same average mean $(\bar{x}=4.06)$, partying gives opportunity for male and female teenagers to have direct physical contact with each other $(\overline{\mathrm{x}}=$ 4.00). The item with the lowest rating of opinion was "Your family accepts that you have a sexual relationship during school age" $(\overline{\mathrm{x}}=2.39)$

\section{Discussions}

\subsection{Imitation of Life}

\subsubsection{Unnecessary Role Models}

It cannot be denied that technological advances in Thailand and throughout the world, have led to the rapid and timely exposure of global news and information. This news and information exposure is in part, a communication about sex and how people show off more freely. The gender expression of celebrities or superstars is seen by many and easily imitated. However, it was found in this study that the respondents' opinions toward celebrities, family members, and friends having influence on their cohabitation were at a moderate level $(\overline{\mathrm{x}}=3.34, \overline{\mathrm{x}}=3.16,(\overline{\mathrm{x}}=2.92$, respectively).

Many of the respondents agreed that they enjoyed the celebrity/superstars' performances but not necessarily their way of life. Even if they saw their friends living together with partners, it did not make them want to imitate their friends' activities. They even followed the saying "I do it my way".

In some instances, the results obtained in this research contradicted results from some previous studies. For examples, 
Kaewkangwan5 indicated that films, television programs and videos had effects on children's thoughts, attitudes, sexual relationships and they took the celebrities as their role models. Friends do have influence on adolescents' decisions, especially on sex and sexual relationships. Close friends were important information resources because friends in the same group had similar characteristics and were of the same age. Role models and friends did have influences on adolescents' healthcare behavior. 6

The results found by this research were also different from Fisher \& Fisher7 who stated that close friends were the main information resources of sex and sexual relationships because friends in the same group had similar characteristics and the same age.

Supansa (a third-year student) viewed that:

"A lot of my friends live together before marriage. They act as they are husbands and wives. When I visit their rooms, I see things that they share. They go to study and come back together. I am not against them but I think it's weird."

Mesa (a first-year student) supported the above view:

"I am not against cohabitation. I think the society is more open nowadays. If I have a boyfriend and want to live with him as a husband and wife, it is because I love him. It is not because I want to imitate my friends, celebrities, or movies."

Worada (a second-year student) pointed out that:

"I have one sister. She's got a job in another town. She comes back home occasionally. She has a boyfriend and they are not married. I believe that they live together and they can manage themselves. However, I don't think I'll live with my boyfriend before marriage like my sister because I am younger." Although the cohabitating behavior was at a high rate, environmental temptations, for examples, celebrities, superstars or friends did not have any impacts on the adolescents' decision to cohabit with their partners. That is to say, some of the respondents, viewed cohabitation as normal and it was other people's personal rights to do it but it did not have an impact on their own decisions.

\subsubsection{The Impacts of Foreign Cultures on Thai Adolescents}

In the past, women's virginity was very important and cohabitation was not acceptable in Thai society because it was considered to disgrace the family. Nevertheless, other cultures, especially, some of those from the West and some from the Far East, which have been spread by the internet, television programs, magazines, films and/or by direct experiences, have changed the Thai adolescents' sexual expectations/attitudes. Even though they had grown up in the context of Traditional Thai culture, 8 it was found in the present study, that the opinions of the respondents toward the influences of foreign cultures, such as American, Japanese and Korean on cohabitations were at a high level $(\overline{\mathrm{x}}=3.55)$. It conformed to the findings of Promma et al. 9 who stated that the foreign cultures had influence on Thai society and changed the behavioral patterns, habits and attitudes of Thai adolescents. Males and females had more freedom to meet and contact each other.

\section{Natthaphong (a fourth-year student) stated that:}

"I must admit that the foreign cultures have influences on the cohabitation of the adolescents. Nowadays, Thai girls are crazy about Koreans and they imitate Koreans' sexual relationship manners."

Preedaphorn (a second-year student) expressed her viewpoint: "I really like Korean stars. I bought many of my belongings from what I see in them. I also like Korean food. I know that Korean superstars live together with their partners. I don't think it's wrong. They don't cause problems to other people."

Accepting both western and eastern cultures in the country has great impact on Thai adolescents' behavior. For instance, the Korean fever is causing imitation behavior in Thai adolescents, in terms of products, foods, clothing, superstars' ways of life and their cohabitation behaviors.

\subsection{Social Contacts}

Currently, the changes in adolescents' sexual behavior are not coming from internal factors only but also from the development of the environment, interaction with family, society, friends, and schools.

According to the concept of social ecology, which points out that an individuals' behavior is determined by the influence of their social environment. This is because a person is always in contact with his/her environment, either directly or indirectly.10 Therefore, spending the evening or night together, makes adolescents feel that they have friends and they are part of a group. Anyone participating in activities such as drinking alcohol or taking drugs in a group is more likely to result in having sex and living together with a person of the opposite sex before marriage, than someone living and spending time alone.

\subsubsection{Nightlife and Cohabitation}

Places of entertainment are social environments. In the past, bars and nightclubs were very popular; the concept of night life has never stopped. These days, discotheques, karaoke bars and pubs have become entertaining habitat for the new generation to spend their evenings. These places are mostly restaurants that serve alcoholic drinks and play loud music and a space for people to sing and dance. It is usually dim and dark inside and that can lead couples to become more intimate, without attracting the attention of others. This in turn can lead to a couple leaving together and if the circumstances allow, they can spend the rest of the night together, which inevitably means having a sexual relationship. If either one or both people concerned have their own accommodation, without the restriction of having parents around, this can be the start of a couple's cohabitation.

It was found in the present study, most of the adolescents viewed that going into places of entertainment and spending an evening together with a member of the opposite sex does not only create a good relationship between friends but could lead them to have sexual intercourse and to eventually cohabit $(\bar{x}=4.06)$. Kaewjai1 1 found the same results in her study which investigated the urban teenagers' night-time behavior: a case study of Ratchada Junction Entertainment Centre in Bangkok. The results showed that a large number of informants spent their evenings with friends. The reason given was that there would be more fun and they had more freedom doing things when they were with their close friends, rather than with other people.

Apatsara (a third-year student) expressed her view as:

"Anyone knows that spending night-life and having sex come together. When I didn't have a boyfriend; I went with my friends and guys tried to chat me up all the time."

Waraphorn (a fourth-year student) supported the above view:

"The atmosphere makes it happen. The songs also stimulate the need. I get lost in the drinks. I used to go spending evenings with my friends. Now, I have a boyfriend, I stop doing it."

Sing-ha (a fourth-year student) stated that:

"I have just had a girlfriend when I am in year four. I met her in the pub near the university. I agree that pubs and sex come together. I don't mean that

going to the pub will end with having sex. It's just makes it easier to build a relationship between the two people."

After dark-entertainment places such as karaoke bars, brasseries, pubs, and discotheques are the places for teenagers to get together. In these places, they can be themselves freely. When the atmosphere is so arousing, having sex may not be avoided. It eventually ends with living together before marriage. 


\subsubsection{Friends and Sex}

Teenagers going out with friends of the opposite sex is becoming common in Thai society, an environment which easily accepts cultural diversity and new technology.12 Male teenagers get together in groups participating in their own activities, while the females spend time with their close friends. They pay more attention to their friends than to their parents.13-14 Finally, if they have chances to be close to each other, sexual relationships of many forms can occur. 14

This study found that going out with a person of the opposite sex was one of the risk factors which eventually leads to sexual intercourse and cohabitation $(\overline{\mathrm{x}}=3.53)$. Explicitly, a high number of respondents agreed that they could be themselves when they spent time with their friends of the opposite sex. When spending time together, they had a chance to help each other and become emotionally involved with each other. It could end up with them having sexual intercourse and cohabitating. This agrees with Ounjit et al.15 who discovered that when teenagers were together in a private place, they had chances to touch each other. They failed to control themselves, lacking consciousness and did not think carefully about preventing risks of sexual behavior. The study of Tanintayangul16 also revealed that teenagers dating and being together with a person of the opposite sex had significant risk of involving sexual behavior at 0.1 level $(r=-.305)$. The others such as Boonchieng 17 and Petkal18 also found it was this behavior that led teenagers to have their first sexual experience. Such behavior included: being with the opposite sex in a private place, meeting and spending time together with friends. There was more opportunity to get close to each other when being alone in a private location with a person of the opposite sex than when they were is a social group. Teenagers also had high sex drives; thus, it could lead them to have sex in the end.19

Pokpong (a third-year student) pointed out that:

"A man and woman are like gas and fire; they shouldn't be together. If the atmosphere allows, it will surely happen."

Sexual activity between adolescents is natural. Their physical and mental development changes according to their personal sex drive. It makes them interested in sex. They develop their relationship with friends of the opposite sex more easily when going out with or meeting in entertainment venues, than when having interactions in the classroom or in a general group situation. The atmosphere, passion and sexual attraction are factors which cause adolescents to spend time together and eventually live together.

\subsection{Social Controls}

\subsubsection{Traditional Thai women reserve themselves}

The traditional value of Thai women is that they are reserved; virginity at marriage is considered essential and valuable. Being reserved does not mean having no interactions with male friends at all but should involve building appropriate relationships without the need to indulge in sexual activities. In Thai society, any women who allows male friends to get physically close to them, lets them touch or embrace them are considered to be 'less of a lady'.12 The result shown in the present study supported such traditional belief as the level of the respondents' opinion was at a high level $(\bar{x}=4.19)$. The respondents agreed they should keep their virginity for their wedding day. Among globalization trends, this is the value that teenagers should uphold. American College of Pediatricians 20 also supports that cohabitation can bring great harm to the relationship. Partners who cohabit, are more likely to be unfaithful in the longer term than those who are married. Many parents believe that the best way to prevent their teenage children from pregnancy is not to have sexual intercourse. Hence, they focus on teaching the daughters to reserve themselves for marriage. Nevertheless, there are a great number of studies such as Shoop and Davidson 21 and Martino et al.22, convincing adolescents to postpone sexual intercourse until marriage, does not help reduce the number of teenage pregnancies. What actually makes teenagers delay their decision to have sex, is giving them knowledge about the risks and responsibilities of sexual behavior. Both males and females need to understand the development of their bodies at this critical period of their lives and how their sexual sentiments are changing. They should be taught not only about the prevention of Sexually Transmitted Infections (STI) and how to prevent them but also about birth control methods, what methods are available, how to use them and how to access birth control services available within the community. Consequently, whenever they have sex, they always protect themselves from STIs and getting pregnant. Unfortunately, this is not always a subject with is taught, either by parents or educational establishments.

To sum up, if parents guide their children to have sex safely, it can reduce the risk of them contracting an STI or becoming pregnant, more effectively than just telling them to avoid having sexual intercourse.23 Undoubtedly, parental attitudes and values concerning premarital sexuality may also affect their own patterns of discipline and childrearing, which, in turn, influence the behavior of their children. 24

Atchara (a first-year student) confirmed that:

"I've never had a boyfriend. I come here to study far away from my parents' care, I've never thought of having sex before the right time. I've seen a lot in Thai society; living together before marriage doesn't work."

Praima (a second-year student) supported the above viewpoint: "I have a boyfriend but we never have sex. I will not let it happen. If my boyfriend loves me truly, he will have to wait till I graduate."

Although teenagers in the present time see cohabitation as a normal thing to do, there are still a lot of them who reserve themselves, have no sexual intercourse before marriage, and keep their virginity for their wedding day. They consider cohabitation as inappropriate behaviors and see it as sexual relation failure.

\subsubsection{Hidden Relationships}

The way of life and sexual behavior of Thai people are determined by traditional attitudes and cultures. For Thais, virginity and no sex before marriage are taken as good conduct. The way in which a Thai woman behaves while being with their boyfriend is important. Thai women's sexual behavior is defined by traditional Thai customs. Teenagers consequently date secretly, to enable them to circumvent their country's traditions.

According to the present study, the respondents' opinion towards this matter was at a high level $(\bar{x}=3.73)$. They agreed that the traditional belief about not living together before marriage is a good thing to follow. However, as their social and emotional developments are taking place, chances for teenagers to have sexual desire are heightened. Teenagers Sexual intercourse may be intentional or by 'accident' but they must keep it secret from their parents because they believe that the parents will not accept their behavior. The level of opinions on their family's approval of students having a sexual relationship, was at a low level $(\overline{\mathrm{x}}=2.39)$. The result was in line with Hurlock 25 who mentioned about teenagers' sexual behaviors. Teenagers are highly curious. Their bodies and minds are ready for reproduction, they are interested in members of the opposite sex, wanting lovers and experiencing sexual desire. Modern social conditions change teenagers' sexual behavior. This is in agreement with Tatro26 who discovered that sexual behavior approval depends on the person's age. Teenagers experience more sexual development and rapid changes in their bodies than at any other time in their life. People aged between 27 and 37 accepted cohabitation behavior in higher numbers than people aged 57 years and over. In addition, Twenge et al.27 also revealed similar result. It showed that the number of people aged 16-33 years old who approved cohabitation was higher than at any other age.

The results found in the study of Srisot and Isarabhakdi28 tilted 'Acceptance of premarital sex of Thai people' also supported that 
some of the working-aged people (25-59 years old), are still attached to the traditional Thai culture. Their parents would never accept cohabitation behavior by their children, especially, their daughters. On the other hand, teenagers had strong bonding between friends. They could accept it if their friends have sex before marriage. As many students revealed:

Worada (a fourth-year student):

"The chance is almost none for parents to accept their teenager children to have sex before marriage. Thai society is not open for this matter. I admit that I have a boyfriend, but I never tell any of my friends that I've ever had sex with him. To my parents, there's no way!"

Wittaya (a third-year student):

"I'm a boy, so it's not a problem for me to have a girlfriend. I've even brought her home."

Sarunya (a first-year student):

"My parents are quite strict. My sister has a boyfriend, but she keeps it a secret. We both know and feel that our parents can't accept it."

Warunya (a third-year student):

"Whenever I go out with my boyfriend, I have to tell my parents that I go out with friends. I'm not confident to let them know. I might wait longer than this. I want to be sure before I tell them." Tanita (a second-year student):

"Truthfully, my family cannot accept me having sex before marriage. But now it happens, I can't do anything about it. I think new generations know how to prevent themselves from getting pregnant. So, it shouldn't be a problem."

Nantida (a fourth-year student):

"My parents know that I have a boyfriend because I am open with them. But one thing I don't tell them is about my sexual relationship. My mother will never accept it for sure."

People in this modern world have more freedom to live their lives as they choose. However, because of the way Thai people raise their children, the family members' opinion, still influences the teenager's decision on choosing a girlfriend or boyfriend. The family is a central institution in the formation of sexual attitudes and behavior because it provides role models.2-4,24 On average, the attitudes of young people today are much less restricted than those of their parents, reflecting either life cycle differences or the impact of social changes.

\subsubsection{Residences}

Residences are one of the factors effecting students the opportunity of cohabitation. Most students do not live with their parents. They rent rooms in condominiums, dormitories or houses, etc. It showed in the present study that the respondents highly agreed $(\bar{x}$ $=3.28$ ) that students living in dormitories or away from parents were more likely to have sexual relationships than if they were living with their parents. It can be said that the freedom of choosing a place to stay, is the main factor in determining whether or not teenagers will cohabit. The respondents admitted that living alone was quite hard for them. Loneliness, having no companions and wanting someone to consult with, were the main reasons why teenagers make the decision to spend their lives with friends of the opposite sex. The results concurred with the research of Wongpetchsanga29 titled 'the premarital sexual permissiveness of the university students'. It was found that the students living in dormitories, flats, and rented houses permitted themselves to have premarital sexual intercourse more than students living with the parents. Wongarsa et al.15 also found the same result in the study of the factors that affect female adolescents' sexual risk behavior. The results revealed that teenagers studying in a higher education level had more freedom as most of them had to stay in dormitories. As a result, there was sexual risk behavior without parental care. On the other hand, Lertsakornsiri's 'Factors Associated with Unwanted Adolescent Women Pregnancy in the Perceived of The First Year Students at Saint Louis College'30 showed that the respondents had opinions toward the risk of premarital sexual intercourse in teenagers living in dormitories at a moderate level $(\bar{x}=2.85)$. That is, the first-year students did not view that residences were risk factors of teenagers engaging in sexual intercourse.

Patpong (a third-year student) revealed that:

I've been living together with my girlfriend for 3 years. There's no problem. I agree that living in a dormitory makes it easier for us to decide to live together."

Somruedee (a second-year student) said that:

"When we are not controlled by our parents, it is normal that we choose the way to spend our own lives."

Sae-ree (a fourth-year student) expressed his opinion:

"When I was at home, I had a girlfriend. I never brought her home, though. When I moved out, we lived together. We've been together since we were in year two. We quarrel sometimes but it's not a big deal."

Warinthorn (a third-year student) stated that:

"Living in unisex dormitories is likely to get the adolescents to have sexual relationship. Of course, girlfriends and boyfriends want to be together."

Studying in a higher education level, students have more opportunities to express their opinions and their living styles than at any other time in their education process. For that reason, it cannot be denied that the students' residences and private accommodation are major factors that provide teenagers with the opportunities to display their individual sexual desires more openly. Cohabitation, therefore, becomes commonplace, especially to those teenagers who have had previous sexual experiences.

\section{The Overall Comparison of Opinion on So- cial Pressures and Cohabitation of Universi- ty Students of Both Sexes}

Table 2 shows the comparison of opinions on social processes and cohabitation of university students. Overall, there were significant differences in male and female opinions, toward social processes and cohabitation of Thai adolescents at the 0.05 level. The overall finding demonstrated that males accepted adolescent cohabitation to a greater extent in all aspects, including imitations, interactions and social controls when compared to females. This indicates that in Thai society, males are able to show their gender expression more overtly than females. They are brought up to be higher in both sexual status and power. This is clearly shown through gender expression, attitude and emotional state toward genders. This corroborates the findings in the study of Rojanawipat 31 which presented that male students' acceptance of premarital sexual behavior, was higher than that of female students. It can be confirmed that males in any eras can express their attitudes and accept sexual behavior more than females.

Table 4: The Overall Multiple Comparisons of the Opinions on Social Processes and Cohabitation of Thai Adolescents Classified by Parenting Styles Regarding Sexual Relationships in the Family

\begin{tabular}{|c|c|c|c|c|c|}
\hline $\begin{array}{c}\text { Parenting Styles regarding } \\
\text { Sexual Relationships in } \\
\text { the Family }\end{array}$ & $\overline{\mathrm{x}}$ & $\begin{array}{c}\text { Stri } \\
\mathrm{ct}\end{array}$ & $\begin{array}{c}\text { Permis- } \\
\text { sive }\end{array}$ & $\begin{array}{c}\text { Authori- } \\
\text { tative }\end{array}$ & $\begin{array}{c}\text { Oth- } \\
\text { ers }\end{array}$ \\
\cline { 2 - 6 } & 3.3 & 3.50 & 3.37 & 3.35 \\
\hline Strict Style & 3.3 & - & $0.000^{*}$ & 0.557 & $\begin{array}{c}0.99 \\
0\end{array}$ \\
\hline Permissive Style & 3.5 & - & - & $0.002^{*}$ & $\begin{array}{c}0.02 \\
3 *\end{array}$ \\
\hline $\begin{array}{c}\text { Authoritative } \\
\text { Style }\end{array}$ & 3.3 & - & - & - & 0.96 \\
& 7 & & & & 6 \\
\hline Others & 3.3 & - & - & - & - \\
\hline
\end{tabular}

Table 5 shows the multiple comparisons of the opinions on social processes and cohabitation of Thai adolescents classified by residences of the students. Overall, the difference in opinions 
of students residing in on-campus dormitories and off-campus dormitories was statistically significant at the confidence level 95\% ( $p<0.05)$.

Table 5: The Multiple Comparisons of the Opinions on Social Processes and Cohabitation of Thai Adolescents Classified by Residences of the Students

\begin{tabular}{|c|c|c|c|c|c|}
\hline Residences & $\overline{\mathrm{x}}$ & $\begin{array}{l}\text { Own } \\
\text { Hom } \\
\text { e }\end{array}$ & $\begin{array}{c}\text { On- } \\
\text { Campus } \\
\text { Dormito- } \\
\text { ry } \\
\end{array}$ & $\begin{array}{c}\text { Off- } \\
\text { Campus } \\
\text { Dormito- } \\
\text { ry } \\
\end{array}$ & $\begin{array}{c}\text { University's } \\
\text { Network } \\
\text { Dormitory }\end{array}$ \\
\hline & & 3.38 & 3.31 & 3.40 & 3.34 \\
\hline $\begin{array}{l}\text { Student's } \\
\text { Own Home }\end{array}$ & $\begin{array}{l}3 . \\
3 \\
8\end{array}$ & - & 0.480 & 0.962 & 0.923 \\
\hline $\begin{array}{l}\text { On-Campus } \\
\text { Dormitory }\end{array}$ & $\begin{array}{l}3 . \\
3 \\
1\end{array}$ & - & - & $0.046^{*}$ & 0.899 \\
\hline $\begin{array}{l}\text { Off-Campus } \\
\text { Dormitory }\end{array}$ & $\begin{array}{l}3 . \\
4 \\
0\end{array}$ & - & - & - & 0.582 \\
\hline $\begin{array}{l}\text { University's } \\
\text { Network } \\
\text { Dormitory }\end{array}$ & $\begin{array}{l}3 . \\
3 \\
4\end{array}$ & - & - & - & - \\
\hline
\end{tabular}

Table 6: The Comparison of the Opinions toward Social processes and Cohabitation of Thai Adolescents with Different Experiences of Sexual Relationships

\begin{tabular}{|c|c|c|c|c|c|c|}
\hline \multirow{2}{*}{ Variable } & \multicolumn{2}{|c|}{$\begin{array}{c}\text { Have Expe- } \\
\text { rience }\end{array}$} & \multicolumn{2}{|c|}{$\begin{array}{c}\text { Never Have } \\
\text { Experience }\end{array}$} & \multirow{2}{*}{$\mathrm{t}$} & $\begin{array}{c}\text { P- } \\
\text { Value }\end{array}$ \\
\cline { 2 - 5 } & $\overline{\mathrm{x}}$ & S.D. & $\overline{\mathrm{x}}$ & S.D. & & \\
\hline $\begin{array}{c}\text { Social Processes and } \\
\text { Cohabitation of Thai } \\
\text { Adolescents }\end{array}$ & 3.51 & .45 & 3.51 & .40 & 7.825 & $.000 *$ \\
\hline
\end{tabular}

Table 6 presents the comparison of the opinions on social processes and cohabitation of Thai adolescents between those who do have experience and those who do not have experience of sexual relationships. It was discovered that the students with different experiences of sexual relationships had significant difference in their opinions, at the confidence level $95 \%(\mathrm{p}<0.05)$. Overall, the university students who had experience in sexual relationships, accepted adolescent cohabitation more than those who did not have sexual experience. Those students who have had sexual experiences view that there is no harm in living together if they can protect themselves from pregnancy and sexually transmitted disease. Nevertheless, the finding in this research also reveals that the majority of parents could not accept this kind of behavior. In their views, cohabitation by their children might possibly cause pregnancy problems and have impact on their studies.

\section{Conclusion and Suggestions}

The new generations' attitudes toward marriage have changed significantly from the past. Premarital Sexual Relationships and cohabitation are more open and accepted by society in many countries. Foreign cultures and technological advances have influences on the new generations' approach to cohabitation.

The cohabitation behavior of the adolescents in the present study was found to be affected by imitation behavior, social interactions and social controls. The adolescents imitate other people's behavior, including actors, singers, friends and family. They also copy the behavior which exists in foreign cultures, by what is called 'an abstract role model' and it is this behavior which has the greatest influence on their decision to cohabit with a member of the opposite sex. Friends do not have much influence on their decisions to live together with their lovers. However, as Thai tradition has limitation on dating, most of the families still, cannot accept their children's cohabitation behavior. Consequently, lovers living together is a secret activity.
According to the study, most students agree that activities organized in the institution, to educate teenagers of the risks associated with sexual relationships, including Sexually Transmitted Infections and Unwanted Pregnancies, would benefit many students by helping them to understand the risks and potential outcome of participating in a sexual relationship, before deciding to cohabit with a member of the opposite sex. These activities should focus on the participation of students and should encourage peer support groups, where advice and information can be exchanged and opinions can be shared which can help individuals find alternative solutions to their own problems. It is essential to involve both male and female students, such activities should be organized in various formats to enable individuals to choose the one that most suits their particular circumstances or interests. Administrators and teachers in educational institutions as well as parents, should be open to such enlightened attitudes toward sexual issues and adolescents' sexual behavior. They should provide explanations according to their understanding of Thai culture to the adolescents, to help them understand the effects of cohabitation prior to marriage. It will make the students more cautious about how to spend their university life.

\section{Acknowledgement}

The research is supported by the Faculty of Humanities and Social Sciences, Mahasarakham University, who granted the funds for the completion of the study. I am thankful to Mahasarakham University Human Resources Development Fund for the fund given to present the research. I am also grateful to all the experts for their expertise that greatly assisted the research, to lecturers from all majors for their time given during the collection of questionnaires and to the students for their valuable time spent on answering the questionnaires and interviews.

Lastly, I would like to express my appreciation to my parents, family, and friends for their support and motivation throughout all this time.

\section{References}

[1] S. Mookaew, Nonmarital Cohabitation: A Case of University Students, Master's Degree Thesis, Thammasat University (2001).

[2] F.F. Furstenberg,Jr., Teenage Pregnancy in a Family Context. Philadelphia, Edited T. Ooms, Temple University Press (1981), pp. 131-164.

[3] G.L. Fox, in Teenage Pregnancy in a Family Context. Philadelphia, Edited T. Ooms, Temple

[4] R. Herceg-Baron and F. F. Furstenberg, Jr., The Childbearing Decision: Fertility Attitudes and Behavior, Edited G. L. Fox, Beverly Hills: Sage (1982), pp. 125-144.

[5] S. Kaewkangwan. Developmental Psychology of People of all Ages, Thammasat University Press, Bangkok (2006).

[6] Busaba Yansomdet. (2009). Adolescents' Risk Behavior: Factors Affecting Sexual Risk Behavior. Retrieved July 27, 2015, from http://www.sahavicha.com/?name= knoledge \&file $=$ readknowledge $\&$ id $=388$.

[7] J.D. Fisher and W.A. Fisher, Psychological Bulletin. 111, 3 (1992).

[8] S. Thato, Journal of Nursing, Naresuan University. 1, 2, (2007)

[9] N. Promma, J. Suparp, K. Chamroonsawasdi, P. Theachaboonsermsak and S. Tansakul, Naresuan Phayao Journal. 6, 2 (2013)

[10] C. Podhisita, Journal of Population and Development. 15, 4 (1995).

[11] J. Kaewjai, Urban Teenager's Nighttime Behavior: A Case Study of Ratchada Junction Entertainment Centre, Bangkok Metropolis, Master's Degree Thesis, Kasetsart University (2007).

[12] W. Ounjit, International Journal of Social Science and Humanity, 1 , 2 (2011).

A. Powwattana, Sexual Risk Behavior Prevention of Adolescents: Participation of Family, School and Community, Thammasat University Press, Bangkok (2009).

[13] Panom Gateman. (2007). Adolescent Development. Retrieved from http://www.psyclin.co.th/new_page_56.htm. 
[14] W. Wongarsa, P. Kongngurn, and S. Vuthiarpa, Journal of Public Health 45, 3 (2015).

[15] N. Tanintayangul, Students' Sexual Risk Behavior in Khon Kaen Municipality, Meung District, Khon Kaen Province, Master's Degree Thesis in Social Development, Khon Kaen University (2009)

[16] W. Boonchieng, W. Tuanrat, W. Fongkaew, and P. Klunklin, Thai Journal of Nursing Council, 28, 1 (2013).

A. Petkal, Factors Relating to Sexual Behavior among Adolescents in the Upper South of Thailand. Master's Degree Thesis in Public Health, Mahidol University (2008).

[17] Ausavin Sangpark, The Effects of Group Counseling based on the Rational Emotive Behavior Theory on the Sexual Behavior of Adolescents, Master's Degree Thesis, Khon Kaen University (2007).

[18] American of Pediatricians Research Center, Institute for Social Research, University of Michigan (2015)

[19] D. Shoop and P. Davidson P, J. Adoles, 17 (1994).

[20] Martino SP, Elliot MP, Corona RP, Kanouse DP, Schuster MM. Beyond the "Big Talk": The Roles of Breadth \& Repetition in Parent-Adolescent Communication about Sexual Topics. Official Journal of the American Academy of Pediatrics, 2009.

[21] S. Chirawatkul, K. Sawangchareon, D. Jongudomkarn, N. Rujiraprasert, Journal of health Science, 21, 5 (2012).

A. Thornton and D. Camburn, Demography, 24, 3 (1987).

[22] University Press (1981), pp. 73-130

[23] E.B. Hurlock, Adolescent Development. McGraw-Hill Kogakusha, Tokyo (1967).

[24] Samantha Tatro. (2015). SDSU Study Reveals Acceptance of Premarital Sex and Same Sex Relationships at an All-Time High. Retrieved from http://www.nbcsandiego.com/ news/local/SDSUStudy-Reveals-Acceptance-of-Premarital-Sex-and-Same-SexRelationships-at-an-All-Time-High302686841.html\#ixzz3b7tw6pSr

[25] Jean M. Twenge, Ryne A. Sherman and Brooke E. Wells. (2015) Changes in American Adults' Sexual Behavior and Attitudes, 1972-2012. Retrieved from http://link.springer.com/article/10.1007\% 2Fs10508-015-0540-2

[26] M. Srisot and P. Isarabhakdi, Phranakhon Rajabhat Research Journal (Humanities and Social Sciences). 1.11, 2 (2016).

[27] P. Wongpetchsanga, Premarital Sexual Permissiveness of University Students: An Exploratory Study. Master's Degree Thesis, Thammasat University (1985).

[28] M. Lertsakornsiri, Journal of The Royal Thai Army Nurses. 15, 1 (2014).

[29] N. Rojanawipat. State University Students' Attitudes on Premarital Sexual Behavior. Master of Arts Thesis (Sociology), Chulalongkorn University (2003).

[30] P. Piyakul, C. Boonsuya, and O. Pachuen. Sexual Risk Behavior among Vocational School Students, Samut Prakan Province. Proceedings of the 1st National Community Health System Conference (NCHSC): Community Health System Driven: Pathways to Health Equity and Sustainability, (2017) July 17; Ambassador Hotel, Bangkok, Thailand 